\title{
Physician versus non-physician CEOs: The effect of a leader's professional background on the quality of hospital management and health care
}

Amol K. Gupta*

Heart, Vascular \& Leg Center, Bakersfield, CA, Unites States

Received: July 5, 2019

DOI: $10.5430 /$ jha.v8n5p47
Accepted: August 29, 2019

Online Published: September 10, 2019

\begin{abstract}
Since 1935, the number of hospitals managed by chief executive officers (CEOs) who are also physicians has decreased by $90 \%$. Today, only $5 \%$ of hospitals in the United States are run by CEOs with a medical degree. However, higher ranked hospitals are more commonly run by CEOs with physician backgrounds. Additionally, overall quality scores in physician-run hospitals were $25 \%$ higher than those run by non-physicians. It is not clear whether this association between physician management and a higher quality of hospital management and health care results from the CEO's professional (medical) background. Considering this, the following editorial discusses what characteristics of physicians and non-physicians may influence their capacity to lead a hospital and how that may impact the quality of management and health care within a hospital. Ultimately, this article aims to further the debate over physician versus. non-physician leadership, building a foundation for further research that may determine the characteristics of a CEO that are essential to guiding positive change in their hospital, refocusing health care back to its original intention: patient care.
\end{abstract}

Key Words: Physicians, Hospital-physician relations, Physician executives, Hospital management

\section{INTRODUCTION}

Trained doctors have historically managed medical centers, but this practice has shifted over the past 80 years. Since 1935, the percentage of hospitals in the United States with physician chief executive officers (CEOs) has decreased by approximately $90 \% .{ }^{[1]}$ While the majority of medical centers have CEOs with business or finance background, only $5 \%$ of hospitals in the United States are run by CEOs with a medical degree. ${ }^{[2]}$ Interestingly, out of the 21 hospitals added to the 2019 United States News and World Report "Best Hospitals" list, more than half were managed by physician CEOs.

In recent years, many medical professionals have begun to question the non-physician management philosophy. ${ }^{[1-6]}$
They argue that, although non-physician executives bring leadership skills and business acumen to a hospital's administration, they often lack the technical and experiential know-how that is crucial to running a hospital. Multiple studies suggest that physician-led healthcare organizations outperform those run by non-physicians. Further research is needed to assess which skill set-business or medical is more valuable and rigorous; qualitative research is needed to confirm and explain these findings.

2. A MAJORITY OF LEADING HOSPITALS ARE PHYSICIAN LED

Although physician CEOs are relatively uncommon, they run some of the best-performing hospitals in the United States. ${ }^{[3]}$

*Correspondence: Amol K. Gupta; Email: vkumar@heartandleg.com; Address: Heart, Vascular \& Leg Center, Bakersfield, CA, Unites States. 
In an analysis of the 2019 US News and World Report (USNWR) "Best Hospitals" list, higher-ranked hospitals were more frequently managed by physician executives. ${ }^{[7]}$ This is a striking finding, given the small percentage of US hospitals with physician CEOs. Furthermore, out of 21 of the hospitals included on USNWR's "Honor Roll" in 2019, 13 were physician-managed, and the top six hospitals on this list (the Mayo Clinic, Massachusetts General Hospital, Johns Hopkins Hospital, Cleveland Clinic, New York-Presbyterian Hospital-Columbia and Cornell and UCLA Medical Center) were physician-run. In an analysis of the 2009 USNWR "Best Hospitals" list by Goodall, quality scores in physicianrun hospitals were found to be $25 \%$ higher than those run by non-physicians. ${ }^{[3]}$

This apparent correlation between physician management and quality supports the hypothesis that physicians are often more effective hospital CEOs in the areas of healthcare performance reflected within the quality score, which includes structure, process, outcomes, and patient-safety index. ${ }^{[3]}$ Of note, high-ranking hospitals typically have larger pools of qualified applicants for leadership positions. The fact that these highly ranked hospitals chose physician applicants for leadership positions is likely to reflect the leadership qualities that these institutions value. ${ }^{[3]}$

In a study conducted in the United Kingdom, ${ }^{[8]}$ researchers created overall hospital management scores for hospitals in the United Kingdom based on measures of clinical and financial quality. Examples include "lean management" (operational effectiveness), performance management (the use of clinical targets for quality and productivity), talent management (recruiting, training, rewarding, and retaining highperforming staff), and clinical leadership (the extent to which physicians manage clinical services). The study identified a clear association between quality and the extent to which physicians contributed to hospital management. Hospitals with more physicians in management roles scored about $20 \%$ higher on these financial and clinical quality scores than those with fewer clinician leaders. ${ }^{[8]}$

\section{Potential ISSUES WITH NON-PHYSICIAN LEADERSHIP}

There are several factors that may explain why the majority of leading hospitals are managed by physician CEOs. The most obvious is the fact that physician CEOs have medical training. Without this training, non-physician administrators often lack technical knowledge of medicine and experiential understanding of hospital life. They do not have the hands-on experience of working on the hospital floor and making difficult, life-altering decisions in a high-stress, often sleep-deprived, environment. ${ }^{[9]}$ This can create a disconnect between hospital staff and administration, often causing tension, mismanagement and frustration that ultimately leads to a lower quality of care for patients. ${ }^{[2]}$

On a broader level, physician and non-physician leaders may have differing opinions about the mission of a hospital. Many critics of the non-physician leadership model argue that nonphysicians tend to shift a hospital's mission toward business and away from patient care. ${ }^{[2]}$ Although finance is an important aspect of any business, in reality, a hospital is more than a business. Its success does not only come from its ability to make money, but from its ability to treat patients. ${ }^{[1]}$

As they are separated from direct patient contact, nonphysician administrators can lose sight of the hospital's patient-oriented purpose. Physicians, on the other hand, are constantly reminded of it as they interact with patients on a daily basis. Their job is to provide the highest quality of care possible and they hold liability if their treatment goes awry. ${ }^{[1]}$ Administrators, no matter how well-intentioned, are not exposed to the same interactions and liabilities of physicians, a reality that can lead non-physician CEOs toward a different set of values and measures of success. ${ }^{[2]}$

\section{THE BENEFITS OF PHYSICIAN LEADER- SHIP}

Research in other fields has shown that appointment of expert supervisors is linked to improved company performance and employee satisfaction. For example, one study found supervisor competence to be the most significant variable in predicting worker job satisfaction. ${ }^{[10]}$ This is true across a range of economic sectors, from sports and education to medicine. ${ }^{[11,12]}$ Indeed, trained medical doctors have the capacity to be excellent hospital CEOs for a variety of reasons. Most obviously, it is due to their understanding of medicine and what it is like to work in a hospital.

Physician CEOs' in-depth understanding of medicine gives them many advantages. Their knowledge can lead to policy decisions that consider human physiology and disease, acknowledging that improved health does not come immediately and that taking care of a patient requires a large amount of patience. ${ }^{[5]}$ Moreover, physicians may better understand that health problems do not exist in isolation. Rather, they are the result of many interrelated anatomical and environmental factors. Subsequently, physicians may better foresee how a policy decision can impact a person's entire health, understanding how one factor interacts with the rest and how those factors will interact in the future.

The personal experience of what it is to be health professional can give physicians more credibility with hospital staff. ${ }^{[2,5,13]}$ 
Naturally, staff are more likely to respect the policies and procedures set by a peer rather than someone they perceive to be an unknowledgeable outsider. The credibility that comes with medical experience is often perceived by the public as well, ${ }^{[5,14]}$ broadening the physician executive's power among hospital and community leaders and allowing them to wield greater influence on decisions that impact patient care.

Although their personalities and psychosocial characteristics vary, most physicians already possess skills that translate well to leadership positions. These theoretical management skills include experience working collaboratively with medical and non-medical staff, making difficult decisions about patient treatment, and remaining professional in high-stress environments. Many physician CEOs further build upon their previous experiences into successful management skills, including negotiating, crisis management, identifying and creating alliances, building networks, persuasion, multi-tasking, and managing cognitive biases. A high degree of credibility, trust of other physicians, and exceptional interpersonal communication skills were found to be amongst the most important skills reported by physician CEOs themselves. ${ }^{[15]}$ Additionally, because physicians have years of practice and experience with human nature, they have a good grasp of human behavior that enables them to become better leaders. ${ }^{[16]}$ However, how these skills compare to non-physicians is not adequately understood. As mentioned above, evidence suggests that physician leadership improves health care quality, but few qualitative studies have been conducted to explain why. Further research needs to be undertaken in order to assess which specific characteristics make physicians better managers and why those characteristics are crucial to running health care facilities.

\section{The POTENTIAL POSITIVE IMPACT OF PHYSICIAN LEADERSHIP}

The University of California Los Angeles (UCLA) Medical Center exemplifies the positive effects of physician leadership. ${ }^{[17]}$ Historically, UCLA was known for its quality medical care and uncomfortable, unwelcoming facilities. ${ }^{[17-19]}$ In 2007, UCLA Medical Center hired a clinical psychiatrist with a master's degree in business administration to serve as its CEO. After spending time meeting with patients and staff to discuss hospital operations, the new CEO, Dr. David T. Feinberg, determined that the problems with UCLA's health system were not deficiencies in technology or science. Rather, patient complaints centered around the hospital's lack of compassion. Using his years of clinical experience, Dr. Feinberg identified ways to make care more compassionate. Some changes were larger, such as altering how medical workers interacted with patients and requiring administrators to spend more time on the hospital floor. ${ }^{[18]}$ While CEO, Dr. Feinberg organized his schedule so that he could spend "a couple hours every day literally sitting on bedsides and asking patients how the care is." ${ }^{\text {[20] }}$ Other changes were small, such as ensuring that bed drapes were closed and that food was served warm. ${ }^{[18]}$ These shifts significantly improved patient and employee satisfaction. ${ }^{[17-20]}$ Today, the UCLA hospital ranks among the best in the United States. ${ }^{[21]}$

It would have been possible for a non-physician CEO to acknowledge and address the problems that UCLA Medical Center faced. However, as a clinical physician, Dr. Feinberg had a better understanding of how to interact with patients and what their treatments required. While listening to patient complaints, he could more effectively and quickly understand what the patient was experiencing and what factors whether medical, infrastructural, or interpersonal - were involved. Overall, Dr. Feinberg was able to use his expertise to shift the UCLA hospital back to its original and most important purpose: patients. ${ }^{[20]}$

\section{WHY AREN'T THERE MORE HOSPITAL CEOS WHO ARE PHYSICIANS?}

Despite the evidence suggesting that physician leaders directly benefit hospitals, only $5 \%$ of US healthcare organizations had physician CEOs in 2014. ${ }^{[2]}$ Several factors underlie this trend. First, non-physician executives usually have completed business or financial degree programs that conferred the managerial, organizational, and financial knowledge and skills that are crucial to leading any organization. ${ }^{[22]}$ Secondly, many physicians are averse to assuming executivelevel leadership roles. Smaller healthcare organizations may require physician CEOs to assume both administrative and clinical roles, while others may contend that, despite their clinical perspective, physician CEOs are more likely to create an organizational vision and culture that is overly narrow and profession-specific. ${ }^{[14]}$ Intensive, prolonged training in one discipline might limit the ability of some physicians to grasp the priorities and needs of non-physician employees and stakeholders. ${ }^{[14]}$

In addition, not every physician has the makings of a successful CEO. As with any profession, a physician CEO requires the capacity to manage successfully. In addition to the clinical knowledge that a physician brings to the role, he or she must also possess strong interpersonal skills, emotional intelligence, financial skills and the ability to develop, communicate, and refine a strategic vision. Moreover, any CEO must desire to continually assess and improve hospital systems and quality of care.

Medical training programs do not normally cultivate these 
qualities or emphasize leadership or administrative career paths. ${ }^{[22]}$ There are several contributing factors for this trend. Medical school curricula are already packed, and many educators balk at sacrificing scientific and clinical learning hours for "softer" skill training. Some medical professionals also perceive administrative work as a lower-status occupation. This sense of intellectual elitism can dissuade students from pursuing management roles or seeking out the training and skills necessary for them. ${ }^{[1]}$ However, in today's complex and demanding healthcare landscape, all physicians need to broaden their understanding of the financial, legislative, and cultural factors that underlie 21 st century medical practice.

\section{AN INCREASING EFFORT TO DEVELOP LEADERSHIP IN PHYSICIANS}

Some medical programs are beginning to incorporate leadership training into their curricula. These include Yale Medicine and the Cleveland Clinic. The Ohio State University Wexner Medical Center has developed a new program for physician executive training called the Talent Management and Leader Development Academy. ${ }^{[13]}$ This program provides training in areas ranging from financial planning and communication to health care law and medical ethics. ${ }^{[13]}$ In a recent program evaluation, $93 \%$ of participants reported that they were satisfied with the program, and $100 \%$ said that they would recommend it to peers. ${ }^{[13]}$

Other universities have launched dual-degree MD-MBA programs for medical students who intend to go into business or administrative roles from early in their careers. At least 60 such programs exist in the United States. ${ }^{[23]}$ They integrate classes on economics, marketing, public health, and other business-related subjects into a medical student's course load. These dual-degree programs seek to bridge the divide between business and medicine by enhancing leadership, finance, and team-building skills before newly graduated MDs enter residency training. [24]

Outside of universities, organizations such as the American Association for Physician Leadership are working to cultivate leadership qualities and skills in physicians. Because of efforts like this and a growing awareness for the benefits of physician leadership, the number of physician executives in the United States is rising. ${ }^{[2]}$ Even non-medical institutions such as the Bill \& Melinda Gates Foundation are choosing to hire physicians into leadership roles. ${ }^{[25]}$ Remarkably, tech-giant Google hired former UCLA CEO Dr. David T. Feinberg, the director that transformed the UCLA medical system, as Vice President of Google Health in 2018. ${ }^{\text {[26] }}$

As the desire for more physician executives increases, space for them has also grown. Since 2013, there has been a $17 \%$ $20 \%$ turnover rate in hospital CEO positions, the highest rates since the American College of Healthcare Executives 50 started recording this data in the 1980s. ${ }^{[27]}$ This means that not only are there more positions available for physician executives; it also implies that more hospitals are dissatisfied with current leadership and are looking for new perspectives to reshape their organizations.

As Dr. Peter Angood and Susan Birk of the American Association for Physician Leadership assert, considering the rising rates of chronic disease, the growing physician and nurse shortages, and the aging population, the current environment presents outstanding opportunities for physicians to develop lasting improvements in health care delivery. ${ }^{[2]}$ Overall, this represents a period of extraordinary opportunities for physicians to provide leadership.

While studies have shown that physicians are more effective hospital CEOs in terms of quality performance measured through structure, process, outcomes, and patient-safety index, there are many additional skills that contribute to good leadership. ${ }^{[3]}$ Effective CEOs must master many skills, among them are technological skills, financial skills, leadership skills, building and maintain board relations, culture, and mentorship. There are few qualitative studies that assess these additional skills, and further research needs to be undertaken in order to assess which skills are integral to effective management in a medical setting and how they make physicians better managers.

\section{Conclusion}

Current evidence suggests that hospitals with physician executives outperform those without. In what may be considered recognition of the positive impact that physician CEOs have on the quality of hospital care and management, there is an increasing effort to cultivate leadership in medical students and qualified physicians through university and non-university business and administration programs. Nevertheless, there is a need to further assess what professional characteristics define the CEOs who manage the leading hospitals and how those characteristics impact hospital quality. Such research will help indicate whether a physician's background is the major mediating factor of improved hospital management and health care. It will also help define what characteristics physician and non-physician CEOs need to develop to ensure that they can guide positive change within their hospital, refocusing health care back to its original intention: patient care.

\section{ACKNOWLEDGEMENTS}

The authors acknowledge Superior Medical Experts for research and editorial assistance.

\section{CONFlicts of InTERest Disclosure}

The authors declare they have no conflicts of interest. ISSN 1927-6990 E-ISSN 1927-7008 


\section{REFERENCES}

[1] Gunderman R, Kanter SL. Perspective: Educating Physicians to Lead Hospitals. Academic Medicine. 2009; 84(10): 1348-1351. PMid: 19881420. https://doi.org/10.1097/ACM.0b013e31 $81 \mathrm{~b} 6 \mathrm{eb} 42$

[2] Angood P, Birk S. The value of physician leadership. Physician Exec. 2014; 40(3): 6-20.

[3] Goodall AH. Physician-leaders and hospital performance: is there an association? Soc Sci Med. 2011; 73(4): 535-539. PMid: 21802184. https://doi.org/10.1016/j.socscimed.2011.06.025

[4] Fares Y, Fares J, Kurdi MM, et al. Physician leadership and hospital ranking: Expanding the role of neurosurgeons. Surg Neurol Int. 2018; 9: 199. PMid: 30386669. https://doi.org/10.4103/sni.sni_ 94_18

[5] Cochran J, Kaplan GS, Nesse RE. Physician leadership in changing times. Healthc (Amst). 2014; 2(1): 19-21. PMid: 26250084. https://doi.org/10.1016/j.hjdsi.2014.01.001

[6] Dwyer AJ. Medical managers in contemporary healthcare organisations: a consideration of the literature. Aust Health Rev. 2010; 34(4): 514-522. PMid: 21108915. https ://doi.org/10.1071/AH0973 6

[7] U.S. News \& World Report Hospital Rankings \& Ratings. 2019. Available from: https://health.usnews.com/best-hospita Is

[8] Castro PJD, Richardons B. A healthier health care system for the United Kingdom. 2008. Available from: https://washburn.edu/faculty/rweigand/McKinsey /McKinsey-Healthier-Care-In-UK.pdf

[9] Lee BY. Study Shows That Doctors Make Better Hospital Leaders. Forbes. 2017.

[10] Artz BM, Goodall AH, Oswald AJ. Boss Competence and Worker Well-Being. ILR Review. 2016; 70(2): 419-450. https ://doi .or g/10.1177/0019793916650451

[11] Goodall AH, Kahn LM, Oswald AJ. Why do leaders matter? A study of expert knowledge in a superstar setting. Journal of Economic Behavior \& Organization. 2011; 77(3): 265-284. https: //doi.org/10.1016/j.jebo.2010.11.001

[12] Goodall AH. Highly cited leaders and the performance of research universities. Research Policy. 2009; 38(7): 1079-1092. https: //doi.org/10.1016/j.respol.2009.04.002

[13] Satiani B, Sena J, Ruberg R, et al. Talent management and physician leadership training is essential for preparing tomorrow's physi- cian leaders. J Vasc Surg. 2014; 59(2): 542-546. PMid: 24360239. https://doi.org/10.1016/j.jvs.2013.10.074

[14] Loh E. Doctors as health managers: an oxymoron, or a good idea? Journal of Work-Applied Management. 2015; 7(1): 52-60. https://doi.org/10.1108/JWAM-10-2015-005

[15] Recupero PR, Rainey SE. The ideal physician executive. Med Health R I. 2006; 89(7): 232-235.

[16] Woo KT. Physician leadership. Singapore Med J. 2007; 48(12): 1069 1073.

[17] Goulston M. Putting the 'Care' Back in Health Care - the UCLA Transformation. 2010. Available from: https://www.huffpost.c om/entry/bringing-back-caring-to-h_b_772524

[18] Feinberg DT. Dr. David T. Feinberg/Interviewer: U. Medicine. UCLA Health U Magazine. 2009.

[19] Feinberg DT. To serve patients is our greatest privilege. Patient Experience Journal. 2014; 1(2): 4-5. https://doi.org/10.35680/2 372-0247. 1044

[20] Carlson B. The Rise of the Chief Experience Officer. Physician Leadersh J. 2015; 2(5): 16-21.

[21] Comarow AH. 2018-19 Best Hospitals Honor Roll and Medical Specialties Rankings. Health. 2018. Available from: https://health.usnews.com/health-care/best-hospita ls/articles/best-hospitals-honor-roll-and-overview

[22] Schwartz RW, Pogge C. Physician leadership: essential skills in a changing environment. Am J Surg. 2000; 180(3): 187-192. https : //doi.org/10.1016/S0002-9610(00)00481-5

[23] MD/MBA Programs. Available from: http://www.mdmbaprogr ams.org/md-mba-programs/

[24] Turner AD, Stawicki SP, Guo WA. Competitive Advantage of MBA for Physician Executives: A Systematic Literature Review. World J Surg. 2018; 42(6): 1655-1665. PMid: 29159602. https : //doi.org/10.1007/s00268-017-4370-3

[25] Robeznieks A. Hospitals hire more doctors as CEOs as focus on quality grows. 2014. Available from: https : //www.modernhealthcare.com/article/20140 510/MAGAZINE/305109988/hospitals-hire-more-doctors -as-ceos-as-focus-on-quality-grows

[26] Pearl R. Why Did Google Hire Geisinger CEO Dr. David Feinberg? Forbes. 2018

[27] Hospital CEO Turnover Rate 2018. 2019. Available from: https : //www . ache.org/about-ache/news-and-awards/ne ws-releases/hospital-ceo-turnover 